\title{
ANALISIS KONDISI PEMESINAN IDEAL UNTUK MENCAPAI UMUR OPTIMAL DARI ROUTING CUTTER DIAMETER 32 mm DAN SLOT DRILL 25 mm PADA MESIN CNC DMC $210 \mathrm{U}$
}

\author{
Deni Fajar Fitriyana ${ }^{1}$, Sulardjaka $^{1}$, Norman Iskandar ${ }^{1}$, Pratama Eka P. S. ${ }^{1}$, dan \\ M.Dzulfikar ${ }^{2}$ \\ ${ }^{1}$ Departemen Teknik Mesin, Fakultas Teknik, Universitas Diponegoro \\ Jl. Prof. H. Soedarto, Tembalang, Kota Semarang 50275. \\ ${ }^{2}$ Jurusan Teknik Mesin, Fakultas Teknik, Universitas Wahid Hasyim \\ J1. Menoreh Tengah X/22, Sampangan, Semarang 50236 \\ *Email: deniifa89@gmail.com
}

\begin{abstract}
Abstrak
Teknologi pemesinan kecepatan tinggi (high speed machining) merupakan salah satu alternatif untuk meningkatkan produktivitas disuatu proses pemesinan. Mesin kecepatan tinggi yang digunakan di PT X adalah mesin CNC DMG Mori DMC 210U yang merupakan mesin CNC 5 axis. Namun dalam aplikasinya, mesin DMG Mori DMC 210 U ini masih belum dapat bekerja secara maksimal. Salah satu penyebabnya adalah umur pahat yang belum optimal. Tujuan dari penelitian ini adalah untuk mengetahui kondisi pemesinan yang sesuai untuk pahat routing cutter (T02) dan pahat slot drill (T31) agar mencapai umur pahat yang optimal berdasarkan data perbandingan nilai teoritis dengan nilai aktual pada mesin CNC DMC 210U. Hasil dari penelitian ini menunjukkan bahwa pada pahat routing cutter (T02), umur optimalnya adalah 300 menit sedangkan umur aktualnya adalah 196,41 menit. Pada pahat slot drill (T31), umur optimalnya adalah 350 menit sedangkan umur aktualnya adalah 330,48 menit. Maka dari itu perlu dilakukan penyesuaian kondisi pemesinan agar umur pahat menjadi optimal, dimana kondisi pemesinan yang sesuai untuk pahat routing cutter (T02) yaitu : kecepatan potong $(V c)=1225,31 \mathrm{~mm} / \mathrm{min}$, kecepatan spindle $(N)=12200 \mathrm{rpm}$, feed rate $(f)=3660 \mathrm{~mm} / \mathrm{min}$, material removal rate $=351,36$ cc/min, sedangkan untuk pahat slot drill (T31) yaitu : kecepatan potong $(V c)=1245,14$ $\mathrm{mm} / \mathrm{min}$, kecepatan spindle $(N)=15862 \mathrm{rpm}$, feed rate $(f)=4758,6 \mathrm{~mm} / \mathrm{min}$, material removal rate $=237,93 \mathrm{cc} / \mathrm{min}$.
\end{abstract}

Kata kunci: high speed machining, routing cutter, slot drill, umur pahat .

\section{PENDAHULUAN}

Dalam proses permesinan biaya operasional dan waktu produksi merupakan salah satu aspek yang paling utama pada pemotongan suatu logam. Biaya operasional yang kecil juga diharapkan juga dapat menekan harga produk yang dihasilkan. Tetapi jika biaya operasional kecil, sedangkan waktu yang digunakan untuk membuat suatu produk tersebut lama, itu akan mengurangi efisiensi proses produksi. Pahat merupakan salah satu hal yang perlu diperhatikan yang dapat mempengaruhi efisiensi proses produksi karena pahat memiliki umur (Marido, 2010), Kerusakan pahat atau umur pahat adalah aspek pertimbangan yang sangat penting dalam mengevaluasi unjuk kerja dari proses pemesinan. Keausan pahat akan semakin besar sampai batas tertentu sehingga pahat tidak dapat digunakan lagi atau pahat telah mengalami kerusakan. Lamanya waktu untuk mencapai batas keausan ini yang didefinisikan sebagai umur pahat (Tool Life Time) (Nugroho, (2010).

Teknologi pemesinan kecepatan tinggi (high speed machining) didefinisikan berdasarkan kecepatan dari spindle mesin tersebut, dimana kecepatannya diatas 18.000 putaran per menit (rpm). Mesin kecepatan tinggi biasa digunakan dalam proses pemesinan bagian-bagian dari pesawat seperti titanium, aluminium dan nikel paduan. Salah satunya terdapat pada PT. X, dimana penggunaan high speed machining menjadi suatu kebutuhan dalam proses pemesinan bagian pesawat. Mesin kecepatan tinggi yang digunakan PT. X adalah mesin CNC canggih generasi lima yaitu DMG Mori DMC 210U yang merupakan mesin CNC yang memiliki 5 axis. Mesin ini memiliki kecepatan putar maksimal sebesar $30.000 \mathrm{rpm}$ 
dan meja kerjanya dapat menahan berat benda kerja sampai $6000 \mathrm{~kg}$, sangat sesuai untuk pembuatan bagian pesawat yang mempunyai ukuran yang cukup besar. Namun dalam aplikasinya, mesin DMG Mori DMC 210 U ini masih belum dapat bekerja secara maksimal.

Salah satu penyebabnya adalah penggunaan umur pahat yang belum optimal. Hal ini diakibatkan karena adanya perbedaan kondisi pemesinan secara teoritis dan kondisi pemesinan aktual di lapangan. Saat proses permesinan berlangsung, pahat telah mencapai batas keausan jika sudah memenuhi dari kriteria berikut (Budiman, 2007):

- Adanya kenaikan gaya potong

- Terjadinya getaran/chatter

- Penurunan kehalusan permukaan

- Perubahan dimensi/geometri produk

Selain kriteria diatas, Umur pahat dapat ditentukan oleh Taylor dan sering disebut dengan Taylor's tool life equation (Childs, 2000). Persamaan hubungan empiris antara kecepatan potong dan umur pahat untuk pahat dituliskan sebagai berikut [4]:

$\begin{aligned} & \text { Vc. } \mathrm{T}^{\mathrm{n}}=\mathrm{C} \\ \text { dimana: } \mathrm{Vc} & =\text { Kecepatan potong }(\mathrm{m} / \mathrm{min}) \\ \mathrm{C} & =\text { Machining constant } \\ \mathrm{n} & =\text { Tool life exponent (it depends } \\ & \text { on tool material) } \\ \mathrm{T} & =\text { Umur pahat (menit) }\end{aligned}$

Dari persamaan diatas, umur dari suatu pahat, sangat dipengaruhi oleh cutting speed. Semakin tinggi Cutting speed, umur pahat akan semakin pendek (Sutopo, 2006). Sedangkan nilai $\mathrm{n}$ untuk beberapa material pahat, adalah berikut (Kalpakjian, 1992):

$$
\begin{array}{ll}
\text { - High speed steels } & \mathrm{n}=0.08-0.2 \\
\text { - Carbides } & \mathrm{n}=0.2-0.6 \\
\text { - Ceramics } & \mathrm{n}=0.5-0.8
\end{array}
$$

Sedangkan machining constant (C) tergantung pada tool dan workpiece. Tujuan penelitian ini adalah menentukan kondisi pemesinan yang sesuai agar pahat yang digunakan pada proses pemesinan ini mencapai umur yang optimal.

\section{METODE PENELITIAN}

Data pada penelitian didapatkan dari studi literatur, hasil penelitian dari divisi cutting tool, hasil simulasi pemesinan menggunakan software Vericut. Data yang diperoleh dibandingkan dengan kondisi pemesinan aktual berdasarkan pengamatan di lapangan pada proses pemesinan closing rib pesawat.
Pengamatan dilakukan pada dua pahat yaitu routing cutter (T02) dan slot drill (T31). Mesin milling CNC DMC $210 \mathrm{U}$ memiliki spesifikasi sebagai berikut :

- Panjang mesin

: $13842 \mathrm{~mm}$

- Tinggi mesin

- Lebar Mesin

: $12320 \mathrm{~mm}$

- Motor Spindel

: $5100 \mathrm{~mm}$

- Kecepatan Putar Spindel : $30.000 \mathrm{Rpm}$

- Langkah Gerak Mesin Sumbu X : 1.800 $\mathrm{mm}$

- Langkah Gerak Mesin Sumbu Y : 2.100 $\mathrm{mm}$

- Langkah Gerak Mesin Sumbu Z : 1.250 $\mathrm{mm}$

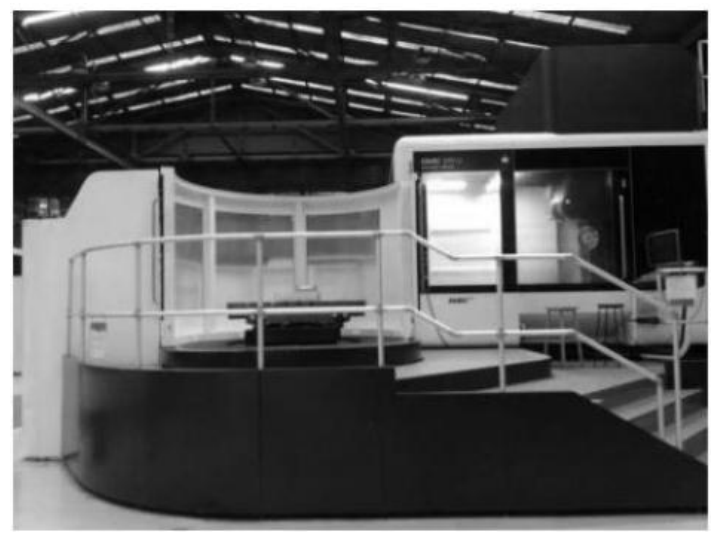

Gambar 1. Mesin CNC DMC 210U

Pahat routing cutter (T02) memiliki spesifikasi sebagai berikut :

- Material : Carbide (Un-coating)

- Diameter : $32 \mathrm{~mm}$

- Jenis Operasi : Roughing

- Umur pahat optimal : 300 menit Sedangkan untuk pahat slot drill memiliki spesifikasi sebagai berikut :

- Material : Carbide K10

- Diameter : $25 \mathrm{~mm}$

- Jenis Operasi : Slot Drilling

- Umur pahat optimal : 350 menit

\section{HASIL DAN PEMBAHASAN}

Pada bagian ini akan dibahas hasil yang telah dicapai dan melakukan pembahasan masalah yang sudah diselesaikan. Tabel 1 menunjukan perbandingan data teoritis yang diperoleh dari software vericut yang ditunjukan pada Gambar 2 dan Gambar 3 dengan kondisi pemesinan aktual. 
Tabel 1. Kondisi pemesinan teoritis dan aktual pada pembuatan closing rib

\begin{tabular}{|l|l|c|c|c|c|}
\hline \multirow{2}{*}{ No. } & \multirow{2}{*}{ Kondisi Pemesinan } & \multicolumn{2}{|c|}{ Routing Cutter (T02) } & \multicolumn{2}{c|}{ Slot Drill (T31) } \\
\cline { 3 - 6 } & & Teoritis & Aktual & Teoritis & Aktual \\
\hline 1 & Kecepatan spindle (rpm) & 22000 & 20000 & 17000 & 17000 \\
2 & Feed Rate (mm/min) & 6600 & 6000 & 5100 & 5000 \\
3 & Cutting speed (mm/min) & 2210,56 & 2009,6 & 1334,5 & 1334.5 \\
4 & Material removal rate (cc/min) & 633,6 & 576 & 255 & 255 \\
5 & Daya mesin (watt) & 475,2 & 432 & 191,25 & 191,25 \\
\hline
\end{tabular}

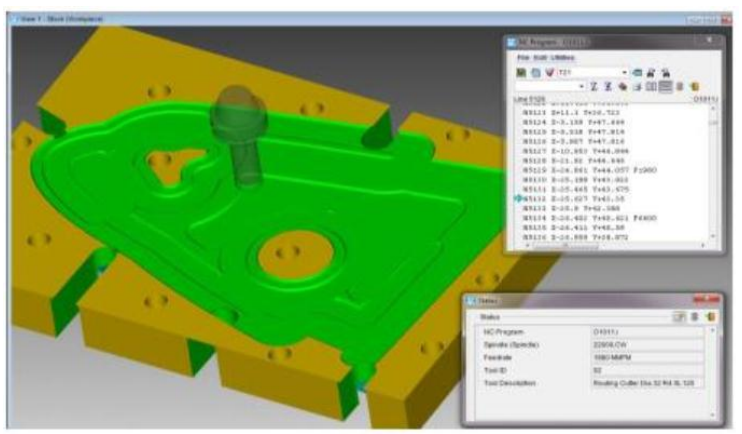

Gambar 2. Simlasi vericut untuk proses pemesinan dengan menggunakan pahat routing cutter (T02)

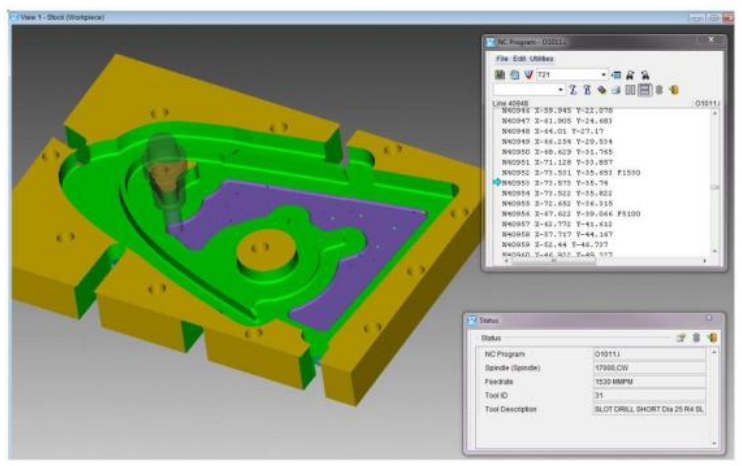

Gambar 3. Simlasi vericut untuk proses pemesinan dengan menggunakan pahat Slot drill (T31)

Tabel 2. Kondisi pemesinan pemesinan untuk perhitungan $\mathbf{n}$

\begin{tabular}{|c|l|c|c|}
\hline No. & Kondisi Pemesinan & Routing Cutter (T02) & Slot Drill (T31) \\
\hline 1 & Vc1 (mm/min) & 300 & 350 \\
2 & T1 (menit) & 1000 & 1000 \\
3 & Vc2 (mm/min) & 5000 & 1500 \\
4 & T2 (menit) & 90 & 300 \\
\hline
\end{tabular}

Berdasarkan data pada Tabel 2, nilai $\mathrm{n}$ dapat dihitung dengan rumus berikut ini (Sutopo, 2006):

$$
n=\frac{\log V c_{2}-\log V c_{1}}{\log T_{1}-\log T_{2}}
$$

Dari hasil perhitungan, nilai $\mathrm{n}$ untuk pahat routing cutter (T02) sebesar 1,168 sedangkan untuk pahat slot drill (T31) sebesar 1,208. Nilai $\mathrm{n}$ hasil perhitungan lebih besar dibandingkan nilai $n$ pada refrensi $(0.2-0.6)$. Hal ini dapat terjadi karena penggunaan proses pemesinan berkecepatan tinggi. Kecepatan potong yang sangat tinggi dapat mengakibatkan perubahan wear mechanism yang dipengaruhi oleh kenaikan suhu yang mengakibatkan nilai eksponen $\mathrm{n}$ melebihi nilai refrensi.

Dari nilai $\mathrm{n}$ tersebut dicari nilai konstanta $\mathrm{C}$ dengan mensubstitusi nilai $\mathrm{n}$ ke persamaan Taylor, pada perhitungan ini menggunakan nilai $\mathrm{Vc}_{2}$ dan $\mathrm{T}_{2}$ dari masing-masing jenis pahat dan didapatkan hasil sebagai berikut :

$\mathrm{Vc} \cdot \mathrm{T}^{1,168}=958352,44$ (Routing cutter)

Vc $\cdot \mathrm{T}^{1,208}=1473851,52$ (Slot drill)

Dari persamaan Taylor tersebut, didapatkan umur pahat untuk kondisi teoritis (optimal) dan kondisi aktual sebagai berikut :

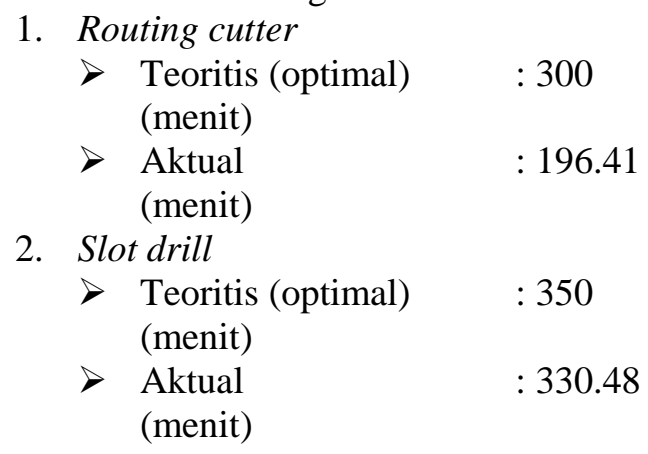

Hasil perhitungan menunjukan umur pahat aktual lebih pendek dari pada umur pahat optimal (teoritis), sehinggu perlu dilakukan penyesuaian kondisi pemesinan agar umur pahat mencapai nilai yang optimal.

Dengan persamaan Taylor, dapat ditentukan nilai kecepatan potong yang ideal agar umur pahat mencapai umur optimal. Karena Vc. $\mathrm{T}^{\mathrm{n}}=$ konstan, maka dapat ditentukan nilai kecepatan potong idealnya. Persamaan umur pahat Taylor tersebut dijelaskan seperti di bawah ini :

1. Routing cutter

$\begin{array}{ll}\text { - } \mathrm{Vc} \cdot 300^{1,168} & =958352,44 \\ \text { - } \mathrm{Vc}_{\text {ideal }} & =1225,31 \mathrm{~mm} / \mathrm{min}\end{array}$

2. Slot drill
- $\mathrm{Vc} \cdot 350^{1,208}$
$=1473851,52$
- $\mathrm{Vc}_{\text {ideal }}$
$=1245,14 \mathrm{~mm} / \mathrm{min}$

Dari hasil perhitungan, didapatkan nilai kecepatan potong ideal untuk Routing cutter dan slot drill, sehingga dapat dilakukan perhitungan untuk kecepatan Spindle $(\mathrm{N})$, Feed 
Rate (F), Material Removal Rate (MRR), dan Daya Mesin (P) seperti yang ditunjukan pada Tabel 3 berikut ini.

\section{Tabel 3 . Data kondisi pemesinan ideal}

\begin{tabular}{|c|c|c|}
\hline \multirow{2}{*}{$\begin{array}{c}\text { Kondisi } \\
\text { Pemesinan }\end{array}$} & \multicolumn{2}{|c|}{ Jenis Pahat } \\
\hline & $\begin{array}{l}\text { Routing Cutter } \\
\text { (T02) }\end{array}$ & Slot Drill (T31) \\
\hline $\begin{array}{l}\text { Recepatan } \\
\text { Potong }\left(V_{c}\right)\end{array}$ & $1225,31 \mathrm{~mm} / \mathrm{min}$ & $1245,14 \mathrm{~mm} / \mathrm{min}$ \\
\hline $\begin{array}{l}\text { Recepatan } \\
\text { Spindle (N) }\end{array}$ & $12200 \mathrm{rpm}$ & $15862 \mathrm{rpm}$ \\
\hline Feed Rate (F) & $3660 \mathrm{~mm} / \mathrm{min}$ & $4758,6 \mathrm{~mm} / \mathrm{min}$ \\
\hline $\begin{array}{l}\text { Material } \\
\text { Removal Rate } \\
\text { (MRR) }\end{array}$ & $351,36 \mathrm{cc} / \mathrm{min}$ & $237,93 \mathrm{cc} / \mathrm{min}$ \\
\hline Daya Mesin (P) & $351,36 \mathrm{cc} / \mathrm{min}$ & $237,93 \mathrm{cc} / \mathrm{min}$ \\
\hline
\end{tabular}

\section{KESIMPULAN}

1, Umur aktual pahat routing cutter (T02) adalah 196,41 menit sehingga belum mencapai nilai umur pahat optimal yaitu $300 \mathrm{~min}$. Sedangkan umur aktual untuk pahat slot drill (T31) adalah 330,48 menit sehingga belum mencapai nilai umur pahat optimal yaitu sebesar $350 \mathrm{~min}$.

2, Kondisi pemesinan yang diperlukan agar umur pahat routing cutter optimal adalah sebagai berikut :

Kecepatan Potong (Vc) : 1225,31 mm/min

Kecepatan Spindle (N) : $12200 \mathrm{rpm}$

Feed Rate (F) $\quad: 3660 \mathrm{~mm} / \mathrm{min}$

Material Removal Rate : $351,36 \mathrm{cc} / \mathrm{min}$

Daya Mesin (P) : 263,52 watt

Tool lifetime : 300 menit

3 , Kondisi pemesinan yang diperlukan agar umur pahat slot drill optimal adalah sebagai berikut : Kecepatan Potong (Vc)

$1245,14 \mathrm{~mm} / \mathrm{min}$

Kecepatan Spindle (N) : $15862 \mathrm{rpm}$

Feed Rate $(\mathrm{F}) \quad: 4758,6 \mathrm{~mm} / \mathrm{min}$

Material Removal Rate : $237,93 \mathrm{cc} / \mathrm{min}$

Daya Mesin $(\mathrm{P}) \quad: 178,44$ watt

Tool Lifetime : 350 menit

\section{DAFTAR PUSTAKA}

Budiman, Hendri, dan Richard, (2007), "Analisis Umur dan Keausan Pahat Karbida untuk Membubut Baja Paduan (ASSAB 760) dengan Metoda Variable Speed Machining Test", Padang, Jurusan Teknik Mesin, Universitas Bung Hatta.

Childs, T., Maekawa, K., Obikawa, T., and Yamane, Y., (2000), "Metal Machining Theory and Applications", by John Wiley \& Sons Inc, New York-Toronto.
Kalpakjian, Serope, 1992, "Manufacturing Engineering and Technology 2nd Edition", Addison Publishing Companya Inc., California.

Marido, Farel R., (2010), “Analisis Umur dan Pengaruh Variabel Proses pada Pemesinan Sekrap Permukaan Baja Karbon Tinggi Terhadap Keausan Pahat Karbida”, Bandar Lampung, Fakultas Teknik, Universitas Lampung.

Nugroho, Sri, dan Hendrikus Senoaji, (2010), "Karakterisasi Pahat Bubut High Speed Steel (HSS) Boehler Tipe Molibdenum (M2) dan Tipe Cold Work Tool Steel (A8)", Semarang, Jurusan Teknik Mesin, Universitas Diponegoro.

Sutopo , Apri , (2006), "Pengaruh Variasi Kecepatan Potong, Feeding Dan Kedalaman Potong Terhadap Umur Pahat HSS Yang Dilapis Aln-Tin-Aln ". Yogyakarta , Jurusan Teknik Mesin , Universitas Negeri Yogyakarta. 